\title{
Effect of socio-demographic status on dental caries in pupils by using a multilevel hurdle model*
}

\author{
Yunes Jahani ${ }^{1}$, Mohammad R. Eshraghian ${ }^{1 \#}$, Abbas R. Foroushani ${ }^{1}$, Keramat Nourijelyani ${ }^{1}$, \\ Kazem Mohammad ${ }^{1}$, Arash Shahravan ${ }^{2}$, Mahin Alam ${ }^{3}$ \\ ${ }^{1}$ Department of Epidemiology and Biostatistics, School of Public Health, Tehran University of Medical Sciences, Tehran, Iran; \\ \#Corresponding Author: eshraghianm@tums.ac.ir \\ ${ }^{2}$ Kerman Oral and Dental Diseases Research Center, Kerman University of Medical Sciences, Kerman, Iran \\ ${ }^{3}$ Adolescents, Youth and Schools Health Unit, Kerman University of Medical Sciences, Kerman, Iran
}

Received 18 April 2013; revised 19 May 2013; accepted 15 June 2013

Copyright (C) 2013 Yunes Jahani et al. This is an open access article distributed under the Creative Commons Attribution License, which permits unrestricted use, distribution, and reproduction in any medium, provided the original work is properly cited.

\section{ABSTRACT}

Introduction: Dental caries is the most prevalent chronic disease among schoolchildren. We aimed to investigate the association between dental caries index and socio-demographic status in schoolchildren by using a multilevel hurdle model. Materials and Methods: A crosssectional epidemiological study was carried out on 906 primary school pupils in Kerman, Iran in 2012. The subjects were selected through a stratified cluster random sampling. At first, the whole target area was stratified according to two geographic areas, the north and south area. Then each area was stratified according to gender. In the next step, several schools were considered as clusters, which were selected randomly in each geographic area and gender strata. All the schoolchildren in these schools were included in this study as samples. Twelveyear-old pupils were examined for dental caries. The dependent variable in this study was the dmft/DMFT index. Eight variables, including socio-demographic information, were collected. Multilevel negative binomial hurdle model was employed for data analysis. Results: The prevalence of caries-free pupils was $30.1 \%$ and the mean $\mathrm{dmft} / \mathrm{DMFT}$ was $3.6 \pm 2.2$. Negative binomial part of the adjusted model showed that the dmft/DMFT adjusted rate for females was $\mathbf{1 . 3 6}$ (95\% Cl: 1.10 - 1.79) times higher than males. Also, the dmft/DMFT adjusted rate for overweight pupils was 0.86 (95\% Cl: 0.74 - 0.98) times lower than those with normal weight. Logistic part of the adjusted model showed that the posibility

\footnotetext{
*The authors declare no conflict of interests.
}

of caries-free state in overweight pupils was 1.95 (95\% Cl: 1.22 - 3.11) times higher than those with normal weight. In addition, pupils whose fathers and mothers were workers and housewives, respectively, and those with a high maternal age were at a greater risk for caries experience than others $(p<0.05)$. Conclusion: BMI, gender, parent's job and mother's age at delivery were factors effecting on dental caries in schoolchildren. These pupils need more attention to dental care.

Keywords: Multilevel Hurdle Model; Dental Caries; Socio-Demographic Status; Primary School Pupils; dmft/DMFT Index

\section{INTRODUCTION}

Dental caries is the most prevalent chronic disease among schoolchildren. It is a cumulative and progressive disease causing pain, infection and possible disfigurement, particularly in children [1]. The World Health Organization's report on oral health provides an overview of global epidemiology of caries, confirming its international pandemic distribution [2]. Nearly $20 \%$ of 2 - 4year-old children have clinically detectable caries, and by age 17 , nearly $80 \%$ of young people have one or more teeth with caries [3]. The majority of studies within the last 10 years in Iran have shown that caries prevalence in pupils is $35 \%-85 \%$ [4-7]. Since children are the most susceptible groups to tooth decay, determining dental caries indices and factors influencing it as one of the most important aims of various research studies in different countries $[2,8]$.

Research has shown that tooth decay is a multi-factorial disease, which is under the influence of numerous factors such as parents' education, parents' job, size of 
the family and other socio-demographic factors [9-11]. Some studies have shown that variables such as BMI, gender and mother's age at delivery are effective on dental caries [12-17]. Understanding the impact of sociodemographic predictors on dental caries could be useful for planning public health policies, thus leading to a better allocation of resources [18].

Statistical modeling plays an important role in understanding caries risk factors [19]. Some researcher found that caries counts are not generally approximated by a normal distribution and common analysis such as t-test and linear regression are not appropriate [10,19-21]. In addition, there are a high proportion of zero scores for dental caries indices. In order to correct results and interpretations, we used a multilevel negative binomial hurdle model. The hurdle model approach is a 2-part count regression method which deals with the phenomenon of excess zeros in data [19].

We aimed to investigate the association between dental caries index and socio-demographic factors in 12year-old schoolchildren living in Kerman, the largest and most important city in southeast Iran, in 2012. We attempt to identify those children at greatest risk to dental caries formation.

\section{METHODS}

\subsection{Data Set Examined}

This cross-sectional study was carried out on 906 twelve-year-old schoolchildren in Kerman, Iran in 2012. In Iran, trained school nurses regularly examine the health information for pupils in primary schools. The dental examination was carried out by school nurses for detection of dental caries in accordance with World Health Organization criteria [22]. The dental examination was noninvasive and x-rays were not used. These health records were used and socio-demographic information was recorded for selected pupils in 2012. The subjects were selected through a stratified cluster random sampling. At first, the whole target area was stratified according to two geographic areas, the north and south area; the northern area generally has a better economic situation than the southern area. Then each area was stratified according to gender. In the next step, several schools were considered as clusters, which were selected randomly in each geographic area and gender strata; all the schoolchildren in these schools were included in this study as samples. The subjects were from ten boy schools and nine girl schools, representing $10 \%$ of the target population.

\subsection{Measurements}

In this research, the $\mathrm{dmft} / \mathrm{DMFT}$ index was used as the dependent variable because it defines the condition of caries in children [22]. This index was calculated as the sum of total decayed $(\mathrm{d} / \mathrm{D})$, missing $(\mathrm{m} / \mathrm{M})$ and filled $(\mathrm{f} / \mathrm{F})$ teeth for primary and permanent dentitions, respectively.

Pupil's BMI (Body Mass Index) was calculated as weight in kilograms divided by the square of the height in meters $\left(\mathrm{kg} / \mathrm{m}^{2}\right)$. Standardized percentile curves of BMI in Iran were used. According to these curves underweight condition is defined as under the 5 th percentile curve, normal as between the 5 th and 85 th percentile, at risk of overweight as higher than the 85th and lower than the 95th percentile and overweight as higher or equal to the 95th percentile [23].

The categorical variables for pupils, studied here, included gender (boy/girl), family size (three, four and five or more) and BMI (underweight, normal, at risk of overweight and overweight). Parental data included father's and mother's education (high school degree or lower/ university), father's job (employee, worker and self-employed), mother's job (employee/housewife) and mother's age at delivery (less than $35 /$ more than 35 years).

\subsection{Reliability and Validity}

For assessing inter-examiner reliability (i.e. school nurses), three school nurses and twenty pupils were selected. Then, dental examinations were carried out by each school nurse on all the twenty pupils. The intraclass correlation (ICC) between the results of examinations (dmft/DMFT) for school nurses was 0.91, demonstrating a high agreement rate between school nurses. In addition, for assessing validity, a dentist carried out dental examinations on the same twenty pupils. Then the results were compared with those of school nurses. Repeated measures analysis of variance did not show any significant differences between the dentist and school nurses in relation to dental examinations $(\rho=0.26)$. In addition, Pearson's correlation coefficients $(\rho)$ between the dentist and each school nurse in relation to dental examinations was high $(\rho=0.92$ for Examiner $1, \rho=$ 0.91 for Examiner 2 and $\rho=0.91$ for Examiner 3), indicating that the results of examinations by school nurses were valid.

\subsection{Statistical Analysis}

Frequency and percentages of caries-free $(\mathrm{dmft} / \mathrm{DMFT}=$ $0)$ pupils and categorical variables were reported. The mean \pm SD for caries severity, dmft/DMFT index, among subjects with any caries was reported. A multilevel negative binomial hurdle model (MNBH) was used to investigate the effect of the variables evaluated on dental caries, which has recently been suggested as an approach that gives a better fit to these types of count data [19].

A backward elimination (B.E) approach was used to exclude independent variables from the adjusted model. 
The final model contained only factors that were significant at a significance level of $\mathrm{p} \leq 0.05$. The odds ratio (OR) and its 95\% confidence interval were reported in relation to the logistic component of the model, corresponding to the caries-free state. The incidence rate ratio (IRR) and its $95 \%$ confidence interval were reported in relation to the truncated negative binomial component of the model, corresponding to caries severity, i.e. dmft/ DMFT index [19].

The Akaike information criterion (AIC) index was used to compare the model used here with Poisson hurdle model, as well as with Poisson and negative binomial regression model. Data were analyzed using programs written with SAS 9.2.

\section{RESULTS}

Table 1 shows different characteristics of the subjects. Of the 906 schoolchildren in this study, most were of normal weight. The majority of the pupils lived in a family of four persons. The majority of the parents was high school graduates or had less education and most were self-employed. The majority of mothers were housewives. In addition, most mothers had been under 35 years at delivery (childbirth).
The caries-free prevalence in the subjects was $30.1 \%$. The mean dmft/DMFT among pupils with any caries was $3.6 \pm 2.2$ (range: $0-9$ ). The caries-free prevalence and the mean dmft/DMFT in the present study are presented in Table 1.

Table 2 shows the results of fitting separate univariate multilevel NBH model between each independent variable and dmft/DMFT index. Logistic parts of these models showed that father's and mother's job, mother's age at delivery and BMI were significant factors for the prevalence of caries-free state $(p<0.05)$. Other variables had no significant effect on the prevalence of caries-free state $(\mathrm{p}>0.05)$. According to truncated negative binomial parts of the hurdle model, only gender and BMI had a significant effect on caries severity $(p<0.05)$. Other variables had no significant effect on caries severity $(\mathrm{p}>$ $0.05)$.

Table 3 shows the results of fitting multiple multilevel $\mathrm{NBH}$ model to dmft/DMFT index, containing only factors that were significant at the level of $p \leq 0.05$. Other factors, which are not reported in Table 3, were not significant and at presence of these included significant factors had a $\mathrm{p}>0.05$. This model shows the effect of each significant factor adjusted for others.

Table 1. Socio-demographic characteristics of 906 pupils in Kerman.

\begin{tabular}{|c|c|c|c|c|}
\hline Variables & & Number (percent) & Caries free ${ }^{*}$ & $\mathrm{dmft} / \mathrm{DMFT}^{* *}$ \\
\hline \multirow{3}{*}{ Gender } & Boy & $487(53.8)$ & $129(26.5)$ & $3.2 \pm 1.9$ \\
\hline & Girl & 419 (46.2) & $144(34.4)$ & $4.0 \pm 2.4$ \\
\hline & 3 & $137(15.1)$ & $43(31.4)$ & $3.7 \pm 2.3$ \\
\hline Family size & 4 & $416(45.9)$ & 137 (32.9) & $3.6 \pm 2.0$ \\
\hline \multirow{2}{*}{ Mother's education } & High school and less & $678(74.8)$ & $208(29.6)$ & $3.7 \pm 2.2$ \\
\hline & University & $228(25.2)$ & $65(32.0)$ & $3.5 \pm 2.0$ \\
\hline \multirow{3}{*}{ Father's education } & High school and less & $644(71.1)$ & $192(29.8)$ & $3.6 \pm 2.2$ \\
\hline & University & $262(28.9)$ & $81(30.9)$ & $3.8 \pm 2.1$ \\
\hline & Employee & 404 (44.6) & $126(31.2)$ & $3.8 \pm 2.2$ \\
\hline Father's job & Worker & $63(7.0)$ & $8(12.7)$ & $3.5 \pm 2.1$ \\
\hline \multirow{2}{*}{ Mother's job } & Employee & $204(22.5)$ & $80(39.2)$ & $3.8 \pm 2.1$ \\
\hline & Housewife & $702(77.5)$ & $193(27.5)$ & $3.6 \pm 2.2$ \\
\hline \multirow{4}{*}{ BMI } & Underweight & $16(1.8)$ & $4(25.0)$ & $4.1 \pm 3.3$ \\
\hline & Normal & $589(65.0)$ & $161(27.3)$ & $3.7 \pm 2.2$ \\
\hline & At risk overweight & $130(14.3)$ & $43(33.1)$ & $3.8 \pm 2.2$ \\
\hline & Overweight & $171(18.9)$ & $65(38.0)$ & $3.3 \pm 2.0$ \\
\hline \multirow{2}{*}{ Mother's age at childbirth } & $<35$ & $570(62.9)$ & $188(33.0)$ & $3.7 \pm 2.1$ \\
\hline & $\geq 35$ & $336(37.1)$ & $85(25.3)$ & $3.6 \pm 2.2$ \\
\hline Total & & $906(100)$ & $273(30.1)$ & $3.6 \pm 2.2$ \\
\hline
\end{tabular}

${ }^{*}$ Frequency (row percentage) for $\mathrm{dmft} / \mathrm{DMFT}=0$ according to each variable; ${ }^{* *} \mathrm{Mean} \pm \mathrm{SD}$ for $\mathrm{dmft} / \mathrm{DMFT}>0$ 
Table 2. Results of fitting multilevel NB hurdle model for dmft/DMFT index (Univariate analysis).

\begin{tabular}{|c|c|c|c|c|c|}
\hline & \multirow{2}{*}{ Variables } & \multicolumn{2}{|l|}{ Logistic part } & \multicolumn{2}{|c|}{ Negative binomial part } \\
\hline & & $\mathrm{OR}^{*}\left(95 \% \mathrm{CI}^{* *}\right)$ & p-value & $\operatorname{IRR}^{* * *}(95 \% \mathrm{CI})$ & p-value \\
\hline \multirow{2}{*}{ Gender } & Boy & 1 & & 1 & \\
\hline & Girl & $1.26(0.35-4.53)$ & 0.70 & $1.35(1.09-1.77)$ & 0.03 \\
\hline \multirow{3}{*}{ Family size } & 3 & 1 & - & 1 & - \\
\hline & 4 & $1.10(0.63-1.85)$ & 0.77 & $0.94(0.80-1.10)$ & 0.48 \\
\hline & $\geq 5$ & $0.75(0.42-1.30)$ & 0.29 & $0.95(0.81-1.20)$ & 0.49 \\
\hline \multirow{2}{*}{ Mother's education } & High school and less & 1 & & 1 & \\
\hline & University & $0.90(0.5-1.5)$ & 0.72 & $0.96(0.83-1.10)$ & 0.61 \\
\hline \multirow{2}{*}{ Father's education } & High school and less & 1 & & 1 & \\
\hline & University & $1.11(0.70-1.69)$ & 0.60 & $1.05(0.92-1.19)$ & 0.43 \\
\hline \multirow{3}{*}{ Father's job } & Employee & 1 & - & 1 & - \\
\hline & Self-employed & $0.99(0.68-1.50)$ & 0.98 & $0.95(0.85-1.07)$ & 0.43 \\
\hline & Worker & $0.25(0.10-0.68)$ & 0.01 & $0.94(0.77-1.16)$ & 0.59 \\
\hline \multirow{2}{*}{ Mother's job } & Employee & 1 & & 1 & \\
\hline & Housewife & $0.58(0.37-0.92)$ & 0.02 & $0.98(0.85-1.14)$ & 0.87 \\
\hline \multirow{4}{*}{ BMI } & Normal & 1 & - & 1 & - \\
\hline & Underweight & $2.15(0.57-8.12)$ & 0.24 & $0.97(0.70-1.40)$ & 0.85 \\
\hline & At risk overweight & $1.50(0.87-2.51)$ & 0.13 & $0.93(0.80-1.10)$ & 0.40 \\
\hline & Overweight & $1.97(1.24-3.12)$ & 0.006 & $0.85(0.73-0.96)$ & 0.03 \\
\hline \multirow{2}{*}{$\begin{array}{l}\text { Mother's age at } \\
\text { childbirth }\end{array}$} & $<35$ & 1 & - & 1 & - \\
\hline & $\geq 35$ & $0.58(0.39-0.86)$ & 0.01 & $1.02(0.91-1.14)$ & 0.75 \\
\hline
\end{tabular}

*Odds ratio; ${ }^{* *}$ Confidence interval; ${ }^{* * *}$ Incidence rate ratio.

Logistic part of the adjusted model showed that odds of caries-free state in pupils with the father being a worker was 0.29 (95\% CI: $0.10-0.78)$ fold than those with the father being an employee $(p=0.02)$. The odds of caries-free pupils with the mother being a housewife was 0.59 (95\% CI: $0.37-0.93)$ fold than that in others (p $=0.03$ ). The odds of caries-free overweight pupils was 1.95 (95\% CI: 1.22 - 3.11) fold than those with normal weight $(\mathrm{p}=0.008)$. Also, the odds of caries-free pupils with older mothers (older than 35 years of age) was 0.55 (95\% CI: $0.37-0.84)$ fold than that in others $(\mathrm{p}=0.008)$. In the present study, only these four factors were important effective factors for caries prevalence.

Truncated negative binomial part of adjusted model showed that the dmft/DMFT adjusted rate for female pupils was $1.36(95 \%$ CI: 1.10 - 1.79) fold than that in boys $(\mathrm{p}=0.02)$. In addition, the $\mathrm{dmft} / \mathrm{DMFT}$ adjusted rate for overweight pupils was 0.86 (95\% CI: $0.74-0.98)$ fold than that in those with normal weight $(p=0.04)$. In this study, only these two factors were important effective factors for caries severity.

In Tables 3, $\sigma^{2}$ (cluster) is the between-cluster variation that show the variation of $\mathrm{dmft} / \mathrm{DmFT}$ index and caries-free state between schools. In our study, these variations were significant $(\mathrm{p}<0.05)$. Therefore, the responses were correlated in each school. That is why we used a multilevel model, which takes into account the correlated nature of responses in each school

To assess goodness of the fit of our model, we compared it with other count models. In this study, the MNBH model had the least AIC compared to other count models, confirming our model $(\mathrm{MNBH}$ AIC $=3424.6$, Poisson hurdle model AIC $=3439.5$, Poisson AIC $=$ 3803.9, negative binomial AIC $=3597.2$ ).

\section{DISCUSSION}

Dental caries, the most common disease of childhood, can be associated with home environment and social and economic factors, which can persist over a lifetime. It is very important to prevent dental caries. The approach to primary prevention should be based on common risk factors. Also, appropriate statistical modeling plays an important role in understanding caries risk factors. In this study, an attempt was made to identify those children at greatest risk of dental caries by using a hurdle model.

This study showed that overweight subjects had higher caries-free prevalence than others. Also, among pupils with caries, overweight pupils had lower caries severity than others. Therefore, obesity was in related to caries 
Table 3. Result of fitting multilevel NB hurdle model ${ }^{*}$ for $\mathrm{dmft} / \mathrm{DmFT}$ index (Multiple analysis).

\begin{tabular}{|c|c|c|c|c|c|}
\hline \multirow{2}{*}{ Variables } & & & \multicolumn{3}{|c|}{ Logistic Part } \\
\hline & & & Adjusted OR & $95 \% \mathrm{CI}$ & p-value \\
\hline \multirow{3}{*}{ Father's job } & Employee & & 1 & - & - \\
\hline & Self-employed & & 1.01 & $0.68-1.49$ & 0.98 \\
\hline & Worker & & 0.29 & $0.10-0.78$ & 0.02 \\
\hline \multirow{2}{*}{ Mother's job } & Employee & & 1 & - & - \\
\hline & Housewife & & 0.59 & $0.37-0.93$ & 0.03 \\
\hline \multirow{4}{*}{ BMI } & Normal & & 1 & - & - \\
\hline & Underweight & & 1.97 & $0.50-7.60$ & 0.30 \\
\hline & At risk overweight & & 1.49 & $0.86-2.60$ & 0.14 \\
\hline & Overweight & & 1.95 & $1.22-3.11$ & 0.008 \\
\hline \multirow{2}{*}{ Mother's age at childbirth } & $<35$ & & 1 & - & - \\
\hline & $\geq 35$ & & 0.55 & $0.37-0.84$ & 0.008 \\
\hline \multicolumn{3}{|l|}{$\sigma^{2}(\text { cluster })^{* *}=1.7$} & & & $<0.0001$ \\
\hline \multirow{2}{*}{\multicolumn{2}{|c|}{ Variables }} & & \multicolumn{3}{|c|}{ Negative binomial part } \\
\hline & & & Adjusted IRR & $95 \% \mathrm{CI}$ & p-value \\
\hline \multirow{2}{*}{ Gender } & Boy & & 1 & - & - \\
\hline & Girl & & 1.36 & $1.1-1.79$ & 0.02 \\
\hline \multirow{4}{*}{ BMI } & Normal & & 1 & - & - \\
\hline & Underweight & & 0.96 & $0.66-1.39$ & 0.82 \\
\hline & At risk overweight & & 0.94 & $0.80-1.10$ & 0.41 \\
\hline & Overweight & & 0.86 & $0.74-0.98$ & 0.04 \\
\hline \multicolumn{2}{|l|}{$\sigma^{2}$ (cluster) $)^{* * *}=0.06$} & & & & 0.0001 \\
\hline \multicolumn{2}{|c|}{$\mathrm{Alph}^{* * * *}=0.06(\mathrm{SD}=0.02)$} & & & & 0.02 \\
\hline \multicolumn{2}{|c|}{ Log-likelihood $=1696.3$} & $\mathrm{AIC}=3424.6$ & & & \\
\hline
\end{tabular}

${ }^{*}$ Backward elimination (B.E) approach; ${ }^{* *}$ Variation of caries-free state between schools; ${ }^{* * *}$ Variation of dmft/DmFT index between schools; ${ }^{* * * *}$ Over dispersion parameter.

prevalence and caries severity. The results of some studies are consistent with those of this study. Macek et al. [12] reported an inverse relationship between caries severity and BMI in US children. Sanchez et al. [13] showed in Mexico City that overweight children had a lower caries index. In a study in Sweden, Norberg et al. [14] showed that pupils with low BMI may be at a greater risk to develop caries. In addition, some studies in Iran are consistent with this study [24,25].

Our study was a cross sectional study and caries and low BMI coexisted in our subjects. Low BMI may be associated with eating habits endangering dental health. Against, the low BMI could be caused by problems related to dental caries such as pain and toothache. These problems affect appetite and may lead to weight loss and lower BMI. In addition, a systematic review revealed contradictory results [26]. So, these findings might also show that further longitudinal study should be conducted to determine whether an association exists between den- tal caries and BMI and to address what factors specific to obesity in children might be protective against dental caries.

In the present study, the caries severity, i.e. $\mathrm{dmft} /$ DMFT, was higher in girls compared to boys. Therefore, girls were at a greater risk to develop more severe carious lesions. Moghimbeigi et al. [15] showed, by using a zero inflated model, that the DMF index of girls was higher than boys, consistent with the results of the present study. Considering the fact that they adjusted extra zeros, high proportions of zero scores for dental caries index, in their analysis and in the present study, reflected the validity of our results about the effect of gender. In this context, some studies have shown more severe carious lesions in girls compared to boys [27-30]. Our findings were expected since permanent teeth erupt $2-10$ months earlier in girls compared to boys [31].

In the present study, father's job had a significant effect on caries prevalence, i.e. pupils whose fathers were 
workers were at a greater risk to develop carious lesions compared to others. In a study in Tehran, Iran, Amanlou et al. [11] found that the caries prevalence in children whose fathers were workers was $60 \%$. In a study in Turkey, caries prevalence in the same children was $81.7 \%$ [32]. The results of these studies are consistent with those of this study. It implies that these pupils need more attention to dental care.

This study showed that mother's job significantly influenced caries prevalence, i.e. pupils whose mothers were housewives were more susceptible to caries than others. In a study in Tehran, Iran, caries prevalence for the same pupils was $69 \%$, which was significantly higher than others [11], consistent with the results of this study. We hypothesized that employed mothers have better economic status and are more knowledgeable about dental health, resulting in the improvement of their children's oral and dental health status.

The results of this study showed that pupils with older mothers had lower caries-free prevalence than others. Therefore, these pupils were at a greater caries risk than others. Sufia et al. [16], in a study in Pakistan, showed that younger age of the mother had a positive effect on the dental health of children, consistent with the results of this study. Niji et al. [17] reported higher odds of caries experience in schoolchildren with younger mothers. In addition, Boitor et al. [33] did not find any statistically significant differences between maternal age at delivery and caries severity, which is not consistent with the results of the present study. These findings should be evaluated further.

Limitations of the present study include its cross-sectional nature, which limits the ability to identify causative factors. Longitudinal designs would increase the knowledge on the determinants of dental caries. In addition, no information was available about nutritional factors and brushing habits of the subjects. It is most appropriate to consider such factors in future studies.

A positive attribute of this study was the statistical analysis that adjusted cluster sampling and extra zero, high proportion of zero scores for $\mathrm{dmft} / \mathrm{DMFT}$ index. In addition, a relatively good representative sample of the population was selected.

In conclusion, the findings of this study indicated that obese schoolchildren had lower prevalence of caries and less caries severity than others. Additionally, the caries severity of the girls was more than boys. In addition, subjects whose fathers and mothers were workers and housewives, respectively, and also those with older mothers were more at risk of caries experience than others. Mother's and father's educational status and family size were not important caries effective factors in the present study.

\section{ACKNOWLEDGEMENTS}

This paper is a part of a research for a $\mathrm{PhD}$ degree at School of Public Health, Tehran University of Medical Sciences (TUMS) and was financially supported by this university. The authors would like to appreciate their support. In addition, we would like to thank Kerman University of Medical Sciences and Education Office in Kerman city, especially all school nurses for their assistance in data collection. We also would like to thank Dr. Harandi for her assistance in dental examinations for assessing validity.

\section{REFERENCES}

[1] Selwitz, R.H., Ismail, A.I. and Pitts, N.B. (2007) Dental caries. Lancet, 369, 51-59. doi:10.1016/S0140-6736(07)60031-2

[2] Petersen, P.E., Bourgeois, D., Ogawa, H., Estupinan-Day, S. and Ndiaye, C. (2005) The global burden of oral diseases and risks to oral health. Bulletin of the World Health Organization, 83, 661-669.

[3] Kopycka-Kedzierawski, D.T., Auinger, P., Billings, R.J. and Weitzman, M. (2008) Caries status and overweight in 2- to 18-year-old US children: Findings from national surveys. Community Dentistry and Oral Epidemiology, 36, 157-167. doi:10.1111/j.1600-0528.2007.00384.x

[4] Kazerouni, K., Mohammadi, N., Ansari, G. and Kamali, Z. (2005) The effects of socio-economic status on dental caries incidence in a group of primary school children, Tehran-2000. Journal of Dental School, 22, 51-59.

[5] Motlagh, M.G., Khanik, G.R.J. and Adiban, H. (2007) Investigation of dental caries prevalence among $6-12$ year old elementary school children in Andimeshk, Iran. Journal of Medical Sciences, 7, 116-120. doi:10.3923/jms.2007.116.120

[6] Momeni, A., Mardi, M. and Pieper, K. (2006) Caries prevalence and treatment needs of 12-year-old children in the Islamic Republic of Iran. Medical Principles and Practice, 15, 24-28. doi:10.1159/000089381

[7] Sadeghi, M., Lynch, C.D. and Arsalan, A. (2011) Is there a correlation between dental caries and body mass index-for-age among adolescents in Iran? Community Dental Health, 28, 174-177.

[8] Edelstein, B.L. (2006) The dental caries pandemic and disparities problem. BMC Oral Health, 6, S2. doi:10.1186/1472-6831-6-S1-S2

[9] Saied-Moallemi, Z., Virtanen, J.I., Tehranchi, A. and Murtomaa, H. (2006) Disparities in oral health of children in Tehran, Iran. European Archives of Paediatric Dentistry, 7, 262-264. doi:10.1007/BF03262563

[10] Solinas, G., Campus, G., Maida, C., Sotgiu, G., Cagetti, M.G. and Lesaffre, E. (2009) What statistical method should be used to evaluate risk factors associated with $\mathrm{dmfs}$ index? Evidence from the national pathfinder survey of 4-year-old Italian children. Community Dentistry and Oral Epidemiology, 37, 539-546. doi:10.1111/j.1600-0528.2009.00500.x

[11] Amanlou, M., Jafari, S., Afzalianmand, N., Omrany, Z.B., 
Farsam, H. and Nabati, F. (2011) Association of saliva fluoride level and socioeconomic factors with dental caries in 3 - 6 years old children in Tehran-Iran. Iranian Journal of Pharmaceutical Research, 10, 159-166.

[12] Macek, M.D. and Mitola, D.J. (2006) Exploring the association between overweight and dental caries among US children. Pediatric Dentistry, 28, 375-380.

[13] Sanchez-Perez, L., Irigoyen, M.E. and Zepeda, M. (2010) Dental caries, tooth eruption timing and obesity: A longitudinal study in a group of Mexican schoolchildren. Acta Odontologica Scandinavica, 68, 57-64. doi:10.3109/00016350903449367

[14] Norberg, C., Stalin, U.H., Matsson, L., Thorngren-Jerneck, K. and Klingberg, G. (2012) Body mass index (BMI) and dental caries in 5-year-old children from southern Sweden. Community Dentistry and Oral Epidemiology, 40, 315-322. doi:10.1111/j.1600-0528.2012.00686.X

[15] Moghimbeigi, A., Eshraghian, M.R., Mohammad, K. and McArdle, B. (2008) Multilevel zero-inflated negative binomial regression modeling for over-dispersed count data with extra zeros. Journal of Applied Statistics, 35, 11931202. doi:10.1080/02664760802273203

[16] Sufia, S., Khan, A.A. and Chaudhry, S. (2009) Maternal factors and child's dental health. Journal of Oral Health \& Community Dentistry, 3, 45-48.

[17] Niji, R., Arita, K., Abe, Y., Lucas, M.E., Nishino, M. and Mitome, M. (2010) Maternal age at birth and other risk factors in early childhood caries. Pediatric Dentistry, 32, 493-498.

[18] Medina-Solis, C.E., Maupome, G., del Socorro, H.M., PerezNunez, R., Avila-Burgos, L. and Lamadrid-Figueroa, H. (2008) Dental health services utilization and associated factors in children 6 to 12 years old in a low-income country. Journal of Public Health Dentistry, 68, 39-45. doi:10.1111/j.1752-7325.2007.00056.x

[19] Preisser, J.S., Stamm, J.W., Long, D.L. and Kincade, M.E. (2012) Review and recommendations for zero-inflated count regression modeling of dental caries indices in epidemiological studies. Caries Research, 46, 413-423. doi:10.1159/000338992

[20] Lewsey, J.D., Gilthorpe, M.S., Bulman, J.S. and Bedi, R. (2000) Is modelling dental caries a "normal" thing to do? Community Dental Health, 17, 212-217.

[21] Lewsey, J.D. and Thomson, W.M. (2004) The utility of the zero-inflated poisson and zero-inflated negative binomial models: A case study of cross-sectional and longitudinal DMF data examining the effect of socio-economic status. Community Dentistry and Oral Epidemiol- ogy, 32, 183-189. doi:10.1111/j.1600-0528.2004.00155.x

[22] World Health Organization (1997) Oral health surveys: Basic methods. 4th Edition, WHO, Geneva.

[23] Hosseini, M., Carpenter, R.G. and Mohammad, K. (1999) Body mass index reference curves for Iran. Annals of Human Biology, 26, 527-535. doi:10.1080/030144699282444

[24] Sadeghi, M. and Alizadeh, F. (2007) Association between dental caries and body mass index-for-age among 6 - 11year-old children in Isfahan in 2007. JODDD, 1, 119-124.

[25] Mohammadi, T.M., Hossienian, Z. and Bakhteyar, M. (2012) The association of body mass index with dental caries in an Iranian sample of children. Journal of Oral Health and Oral Epidemiology, 1, 29-35.

[26] Kantovitz, K.R., Pascon, F.M., Rontani, R.M. and Gaviao, M.B. (2006) Obesity and dental caries-A systematic review. Oral Health \& Preventive Dentistry, 4, 137-144.

[27] Ur Rehman, M.M., Mahmood, N. and Ur Rehman, B. (2008) The relationship of caries with oral hygiene status and extra-oral risk factors. Journal of Ayub Medical College, Abbottabad, 20, 103-108.

[28] Elias-Boneta, A.R., Psoter, W., Elias-Viera, A.E., Jimenez, P. and Toro, C. (2006) Relationship between dental caries experience (DMFS) and dental fluorosis in 12-year-old Puerto Ricans. Community Dental Health, 23, 244-250.

[29] De Almeida, C.M., Petersen, P.E., Andre, S.J. and Toscano, A. (2003) Changing oral health status of 6- and 12-year-old schoolchildren in Portugal. Community Dental Health, 20, 211-216.

[30] Okeigbemen, S.A. (2004) The prevalence of dental caries among 12 to 15 -year-old school children in Nigeria: Report of a local survey and campaign. Oral Health \& Preventive Dentistry, 2, 27-31.

[31] Wedl, J.S., Danias, S., Schmelzle, R. and Friedrich, R.E. (2005) Eruption times of permanent teeth in children and young adolescents in Athens (Greece). Clinical Oral Investigations, 9, 131-134. doi:10.1007/s00784-004-0295-y

[32] Namal, N., Vehit, H.E. and Can, G. (2005) Risk factors for dental caries in Turkish preschool children. Journal of Indian Society of Pedodontics and Preventive Dentistry, 23, 115-118. doi:10.4103/0970-4388.16881

[33] Boitor, C.G., Fratila, A., Stanciu, L., Pitic, A. and Acu, A.M. (2011) Socio-economic factors and hygienic foodillness involved in determining dental caries of 12-yearold children in rural and urban area. Review of Research and Social Intervention, 33, 167-177. 